KAWISTARA

\begin{tabular}{lll} 
VOLUME 5 & No. 1, 22 April 2015 & Halaman 1-98 \\
\hline
\end{tabular}

\title{
KETIKA CINTA BERTASBIH TRANSFORMASI NOVEL KE FILM
}

\author{
Siti Isnaniah \\ Institut Agama Islam Negeri Surakarta \\ Email: niahisna62@yahoo.com
}

\begin{abstract}
One study of ecranisation is a transformation from novel to film. One of the novels deserves to be studied are El Shirazy's Ketika Cinta Bertasbih (KCB) 1 and 2. The film is based on a novel, including the reception of research resources in the form of adaptations in other media. The presence of KCB novel which filmed later is the phenomenon of ecranisation which siphon attention from the public from all backgrounds and ages. The differences which frequently arise in ecranisation have often caused by the differences in the literary system (novel) and film. The differences which frequently arise in ecranisation have often caused by the differences in the literary system (novel) and film. The technical issues, such as media novel form of words and language, meanwhile the main media of film is an audio-visual (sound and picture). Therefore, it would be reasonable if the film is different from the novel. In the KCB novel and film, the differences that exist are not only technical problems, but a deliberate distinction with a specific purpose as well. Based on the facts above, the KCB novel and film have many differences caused by the reception process through $\mathrm{KCB}$ novel conducted by film production (screenwriter, director, and producer). This case is a problem which becomes question in the mind of the readers of the KCB novel. The literary reception towards KCB novel which eventually lead to the film is a creative act as a reader.
\end{abstract}

Keywords: Ecranisation, KCB, Reception, Literary

\begin{abstract}
ABSTRAK
Salah satu kajian ekranisasi adalah transformasi bentuk dari novel ke film. Salah satunya yang pantas dikaji adalah film karya El Shirazy, Ketika Cinta Bertasbih 1 dan 2. Film yang diangkat dari sebuah novel termasuk dalam sumber penelitian resepsi yang berupa saduran dalam media lain. Hadirnya novel KCB yang kemudian difilmkan adalah fenomena ekranisasi yang banyak menyedot perhatian masyarakat luas dari segala kalangan dan usia. Perbedaan yang sering muncul dalam ekranisasi selama ini sering disebabkan oleh perbedaan sistem sastra (novel) dan film. Hal-hal teknis seperti media novel yang berupa kata-kata dan bahasa, sementara media utama film adalah audio visual (suara dan gambar). Oleh sebab itu akan menjadi wajar jika film berbeda dengan novel. Dalam novel dan film KCB, perbedaan yang ada bukan sekedar karena masalah teknis, tetapi perbedaan yang disengaja dengan tujuan tertentu. Berdasarkan kenyataan di atas, novel dan film KCB banyak perbedaan yang disebabkan oleh proses resepsi terhadap novel KCB yang dilakukan oleh produksi film (penulis skenario, sutradara, dan produser). Hal ini adalah sebuah permasalahan yang sering menjadi pertanyaan di benak para pembaca novel KCB. Resepsi terhadap novel KCB yang akhirnya menimbulkan film adalah suatu tindakan yang kreatif sebagai pembaca.
\end{abstract}

Kata Kunci: Ekranisasi, KCB, Resepsi, Sastra 


\section{PENGANTAR}

Setelah lama mengalami kevakuman, dunia perfilman Indonesia saat ini telah bangkit. Hal tersebut ditandai dengan booming-nya film-film yang bergenre cerita remaja, horor, maupun cerita religi. Film-film yang berkembang saat ini dianggap merepresentasi karya yang mewakili semangat perkembangan dalam masyarakat Indonesia kontemporer dengan kompleksitas problem yang dihadapi. Boooming industri perfilman Indonesia saat ini tentunya tidak terlepas dari kerja keras para sineas-sineas profesional untuk membuat fim yang berkualitas.

Sekarang ini film tidak hanya dipandang sebagai hiburan semata, melainkan juga dianggap merepresentasikan persoalan yang sedang berkembang. Sebagai produk budaya, film sarat akan nilai, idiologi, dan kuasa tertentu. Film diakui memiliki pengaruh yang kuat dan lebih peka terhadap budaya masyarakat daripada sebuah monografi yang dibuat oleh sejarahwan. Oleh karena itu, film memberikan petunjuk berharga tentang pandangan kontemporer terhadap realitas hidup. Film memainkan peran dalam mendefinisikan realitas, mengidentifikasi dan kemudian memformulasikan ke dalam bentukbentuk simbolik yang sudah terolah, menjadi sebuah "representasi". Representasi dalam teks media dapat dikatakan berfungsi secara ideologis sepanjang represetasi itu berkenaan dengan dominasi dan eksplorasi.

Pendekatan yang digunakan dalam studi film pun berasal dari banyak disiplin ilmu, seperti linguistik, psikologis, kriktik sastra, dan sejarah, termasukjuga bermacam-macam posisi politik, seperti marxisme, feminisme, dan nasionalisme. Bagaimanapun, alasan utama mengkaji film adalah sebagai sebuah sumber hiburan dan memiliki peran penting dalam kebudayaan. Karena film bertema nilainilai ke-islaman berpotensi menpengaruhi kebudayaan masyarakat, ia tentu saja tidak terlepas dari kepentingan-kepentingan di sekitarnya. Kepentingan sutradara, pemilk modal, dan ideologi agama memilki peran dalam sebuah produksi film.
Persoalan agama dalam film tidak bisa dilepaskan dari setting wacana ideologis yang berkembang dalam masyarakat. Tidak bisa dipungkiri bahwa ada beberapa alasan kenapa tema-tema yang terkait dengan Islam menjadi tema yang cukup digemari oleh kalangan industri film. Islam adalah agama dengan pemeluk mayoritas di Indonesia. Dengan kata lain, umat Islam merupakan audiens film yang paling banyak dibandingkan para pemeluk agama lain. Mayoritas jumlah pemeluk dan penonton itulah yang kemudian menjadi asumsi pasar bahwa film-film yang menyuguhkan representasi nilai-nilai Islam pasti akan menarik minat dari penonton untuk melihatnya sehingga lebih menguntungkan.

Menonton film merupakan kegiatan sosial kultur yang sangat komplek, yang di dalamnya dapat terjadi pertarungan makna di antara penonton dengan film yang mempunyai banyak kepentingan dan ideologi tertentu. Film dianggap memiliki peran untuk merepresentasikan realitas dalam bentuk simbol yang telah mengalami komodifikasi.

Di antara karya yang menarik untuk dikaji secara resepsi satra dan ekranisasi adalah Ketika Cinta Bertasbih (KCB) karya Habiburrahman El Shirazy. Untuk mengkaji karya-karya tersebut dengan pendekatan resepsi sastra dan ekranisasi, pembaca terlebih dahulu harus memahami unsurunsur struktural yang terdapat dalam sebuah karya. Pembaca belum begitu mengenal novel $\mathrm{KCB}$, setelah novel tersebut sukses luar biasa diikuti pula dengan kesuksesan filmnya. Film KCB distradarai oleh Chairul Umam dan penulis naskah skenario adalah Imam Tantowi. Production House yang memproduksi film tersebut adalah sinemArt.

Film yang diangkat dari sebuah novel termasuk dalam sumber penelitian resepsi yang berupa saduran dalam media lain,proses adaptasi dari novel ke bentuk film ini disebut ekranisasi (Eneste, 1991: 60). Dia menjelaskan bahwa novel dinikmati dengan cara membaca, sementara film dinikmati dengan menontonnya. Begitu juga perubahan 
dari sebuah bentuk kesenian yang bisa dinikmati kapan saja dan di mana saja, yaitu saat membaca novel, menjadi sebuah bentuk kesenian yang dinikmati pada saat tertentu dan tempat-tempat tertentu pula. Ekranisasi berarti pula apa yang dinikmati selama berjam-jam atau berhari-hari, harus diubah menjadi apa yang dinikmati (ditonton) selama 90 sampai 120 menit.

Banyak film yang diangkat dari sebuah novel, misalnya film Harry Potter diadaptasi dari novel karya J. K. Rowling yang berjudul Harry Potter, film The Lord of the Rings dari novel The Lord of the Rings karya Tolkien tahun 1954, film Doctor Zhivago adaptasi dari novel Doctor Zhivago karya Boris Pasternak, dan sebagainya. Ekranisasi di Indonesia juga bukan hal yang baru lagi. Banyak film Indonesia yang juga diadaptasi dari novel, misalnya film Darah dan Mahkota Ronggeng karya Ami Priyono diadaptasi dari novel Ronggeng Dukuh Paruk karya Ahmad Tohari, film Jangan Ambil Nyawaku diangkat dari novel karya Titi Said, film Roro Mendut karya Ami Priyono diangkat dari novel Roro Mendut karya Y. B. Mangunwijaya, film Atheis karya Sjumandjaja diadaptasi dari novel Atheis karya Achdiat K. Mihardja, film Si Doel Anak Betawi karya Sjumandjaja diadaptasi dari novel Si Doel Anak Betawi karya Aman Dt. Madjoindo, film Salah Asuhan karya Asrul Sani diadaptasi dari novel Salah Asuhan karya Abdoel Moeis, film Ca Bau Kan karya Nia Dinata diangkat dari novel Ca Bau Kan karya Remy Sylado, film Badai Pasti Berlalu karya Teddy Suriatmadja diadaptasi dari novel Badai Pasti Berlalu karya Marga T., film $A A C$ karya Hanung Bramantyo diadaptasi dari novel $A A C$ karya Habiburrahman El Shirazy, film Ketika Cinta Bertasbih (KCB) 1 dan 2 diangkat dari novel KCB1 dan 2 karya Habiburrahman El Shirazy, film Perempuan Berkalung Sorban diangkat dari novel yang sama karya Abidah El Khalieqy, film Emak Ingin Naik Haji ditayangkan berdasarkan cerpen Asma Nadia dengan judul Emak Ingin Naik Haji.

Sementara itu, sinetron yang diangkat dari novel di antaranya Siti Nurbaya karya
Dedi Setiadi yang diangkat dari novel Siti Nurbaya karya Marah Rusli yang dilanjutkan dengan Sengsara Membawa Nikmat karya Tulis Sutan Sati (TVRI), serial Lupus karya Hilman Hariwijaya dan Karmila karya Marga T. ditayangkan di Indosiar, serta beberapa lagi yang ditayangkan di RCTI di antaranya Padamu Aku Bersimpuh karya Gola Gong, Cintaku di Kampus Biru karya Ashadi Siregar, Keluarga Cemarakarya Arswendo Atmowiloto, dan Cinta Berkalang Noda karya Mira Wijaya. Fenomena seperti itu juga sempat booming ketika banyak sinetron bertema religi yang ceritanya diadaptasi dari kisah-kisah nyata yang termuat dalam majalah Hidayah.

Begitu juga dengan proses adaptasi dari film ke dalam novel. Di luar negeri, beberapa contoh novel hasil adaptasi dari film di antaranya Dead Poets Soeciety karya N. H. Kleinbum yang diadaptasi dari film karya Tom Schulman dengan judul yang sama. Begitu pula pada pertengahan tahun 2003, cerita film Matrix karya Wachowski bersaudara dibuat novelnya dengan judul Matrix Warrior: Being the One oleh Jake Horsley.

Di Indonesia sendiri, menurut Hadiansyah (2006) bahwa pengadaptasian novel dari film belum lama dilakukan, seperti pada novel anak Jenderal Kecil karya Gola Gong (Dar! Mizan, 2002) yang diadaptasi dari telesinema Jenderal Kecil yang disiarkan oleh RCTI pada bulan Juli 2002 dalam rangka Hari Anak Nasional. Sementara pada film layar lebar terjadi pada film Biola Tak Berdawai karya Sekar Ayu Asmara yang dinovelkan oleh Seno Gumira Ajidarma (Akur, 2004), 30 Hari Mencari Cinta dinovelkan oleh Nova Rianti Yusuf (Gagas Media, 2004), film Brownies karya Hanung Bramantyo dinovelkan oleh Fira Basuki, dan film Rindu Kami Pada$M u$ karya Garin Nugroho dinovelkan oleh Garin Nugroho dan Islah Gusmian (2005), cerpen Tentang Dia!!!. Karya Melly Goeslow (Gagas Media, 2005) yang ditulis ke dalam bentuk skenario Titien Wattimena, difilmkan oleh sutradara Rudi Sudjarwo, kemudian dinovelkan kembali oleh Moammar Emka (Gagas Media, 2005). 
Hadirnya novel KCB yang kemudian difilmkan adalah fenomena ekranisasi yang banyak menyedot perhatian masyarakat luas dari segala kalangan dan usia. Perbinacangan seputar KCB tidak hanya dilakukan secara nonformal pada kehidupan sehari-hari, namun menjadi tema perbincangan yang menarik dalam forum-forum seminar yang sifatnya resmi khususnya di dunia kampus. Tidak hanya itu, di dunia maya pun perbincangan sangat seru dilakukan oleh para blogger. Saat sedang online dengan jaringan internet, akan banyak sekali ditemukan artikel atau obrolan seputar $\mathrm{KCB}$ yang sifatnya tidak resmi. Di televisi pun, tema seputar KCB sering menjadi topik utama dalam berbagai perbincangan dalam acara-acara talk show. Tidak ketinggalan pula, berbagai infotainment di televisi juga menjadikan fenomena KCB sebagai sajian utama. Bahkan para pejabat negara juga sempat memberikan apresiasi dengan ikut menontonnya di bioskop. Namun, pendapat yang beredar selama ini di masyarakat masih asumtif dan subjektif. Pendapat ini tidak didasarkan pada penelitian lapangan untuk membuktikan kebenaran.

Perbedaan yang sering muncul dalam ekranisasi selama ini sering disebabkan oleh perbedaan sistem sastra (novel) dan film. Halhal teknis seperti media novel yang berupa kata-kata dan bahasa, sementara media utama film adalah audio visual (suara dan gambar). Oleh sebab itu akan menjadi wajar jika film berbeda dengan novel. Dalam novel dan film $\mathrm{KCB}$, perbedaan yang ada bukan sekedar karena masalah teknis, tetapi perbedaan yang disengaja dengan tujuan tertentu. Berdasarkan kenyataan di atas, novel dan film $\mathrm{KCB}$ banyak perbedaan yang disebabkan oleh proses resepsi terhadap novel KCB yang dilakukan oleh produksi film (penulis skenario, sutradara, dan produser). Hal ini adalah sebuah permasalahan yang sering menjadi pertanyaan di benak para pembaca novel KCB. Oleh sebab itu resepsi terhadap novel KCB yang akhirnya menimbulkan film pantas dilakukan.

\section{Resepsi Sastra}

Secara definitif, resepsi sastra berasal dari kata recipere (Latin), reception (Inggris), yang berarti sebagai penerimaan atau penyambutan pembaca. Ratna (2009: 165) mendefinisikan sastra sebagai pengolahan teks, cara-cara pemberian makna terhadap karya sehingga dapat memberikan respon terhadapnya. Respon tersebut tidak dilakukan antara karya dengan seorang pembaca, melainkan pembaca sebagai proses sejarah dalam periode tertentu. Jadi, kondisi sosial kultural pembaca pada suatu masa turut berpengaruh terhadap hadirnya sebuah karya.

Pradopo (2008: 206) menyatakan bahwa karya sastra bisa dikaji dengan menggunakan metode estetika resepsi atau estetika tanggapan, yakni estetika (ilmu keindahan) yang didasarkan pada tanggapan-tanggapan atau resepsi-resepsi pembaca terhadap karya sastra. Pendapatnya berbeda dengan Nyoman Kutha Ratna. Karena Rachmat Djoko Pradopo menyatakan bahwa dari dahulu sampai sekarang karya sastra itu selalu mendapat tanggapan-tanggapan pembaca baik secara perseorangan maupun secara bersama-sama atau secara masal, sedangkan Ratna membatasi respon pembaca tidak dapat dilakukan antara karya dengan seorang pembaca, melainkan pembaca sebagai proses sejarah, pembaca dalam periode tertentu. Penulis akan lebih cenderung mendefinisikan sastra sebagai tanggapan-tanggapan atau resepsiresepsi pembaca, baik secara perseorangan maupun secara bersama-sama atau secara masal terhadap karya sastra, serta tanggapantanggapan tersebut dipengaruhi oleh proses sejarah, pembaca dalam periode tertentu.

Senada dengan dua pendapat di atas, Sastriyani (2001: 253) mendefinisikan resepsi sastra sebagai aliran sastra yang meneliti teks sastra dengan mempertimbangkan pembaca selaku pemberi sambutan atau tanggapan. Dalam memberikan sambutan atau tanggapan tersebut dipengaruhi oleh faktor ruang, waktu, dan golongan sosial.

Berkaitan dengan faktor ruang, waktu, dan golongan sosial atau proses sejarah 
pembaca dalam menanggapi karya sastra, Teeuw (1988: 327) menyatakan bahwa resepsi terhadap karya sastra tidak hanya dilakukan oleh pembaca yang sezaman dengan penulis, tetapi juga resepsi oleh angkatan pembaca yang berturut-turut sesudah masa penciptaan karya sastra tersebut. Junus (1985: 1) menyatakan bahwa resepsi sastra dimaksudkan bagaimana "pembaca" memberikan makna terhadap karya sastra yang dibacanya sehingga dapat memberikan reaksi atau tanggapan terhadapnya. Tanggapan tersebut dapat bersifat pasif, yaitu bagaimana seorang pembaca dapat memahami karya itu atau dapat melihat hakikat estetika yang ada di dalamnya, maupun bersifat aktif, yakni bagaimana pembaca mampu "merealisasikan" karya sastra. Oleh sebab itu, dalam memahami arti dalam teks karya sastra terdapat dua pandangan, yaitu (1) Arti sebuah teks karya sastra dapat dilihat dengan hanya mempelajari teks itu sendiri, dengan menggunakan alasan-alasan yang ditemukan dalam teks itu. (2) Arti sebuah teks karya sastra hanya dapat ditemukan dengan menghubungkan teks itu dengan penulisnya, mengembalkannya kepada penulisnya.

Tetapi resepsi sastra mengambil sikap lain. Pada dasarnya diakui adanya hakikat polisemi pada sebuah karya sastra. Tapi bukan tidak mungkin, seorang pembaca dalam suatu waktu tertentu hanya akan melihat satu "arti" saja. Atau ia memberikan tekanan kepada suatu "arti" tertentu, dengan mengabaikan atau menganggap tak penting "arti" lainnya (Junus, 1985: 2).

Sangidu (2002) menekankan faktor pembaca dalam komunikasi memiliki pengertian yang bermacam-macam, salahsatunya adalah pembaca nyata (real reader), pembaca dalam arti fisik, yakni orang yang melaksanakan tindakan membaca. Pembaca dalam kelompok ini meliputi pembaca peneliti (resepsinya berupa reaksi atau tanggapan terhadap teks sastra seperti yang dipahaminya dan berdiri dalam proses pembacaan) dan pembaca umum (resepsinya berupa reaksi atau tanggapan terhadap teks sastra seperti yang dipahaminya dan berdiri di luar proses pembacaan).

Sayuti (2000: 41) menyatakan bahwa sebagai sebuah proses komunikasi, teks dan pembaca memerankan dua buah fungsi. Pertama, menandai hubungan skema tekstual. Dalam hal ini, pembaca tidak boleh seenaknya menyusun ikatan yang hilang hanya berdasarkan pengalaman dan harapan miliknya, tetapi berdasarkan kesesuaiannya dengan struktur tekstual. Kedua, dunia teks literer diciptakan untuk pembaca dari perspektif yang berubah-ubah. Oleh sebab itu tugas pembaca adalah menghubungkan perspektif itu agar sesuai dengan struktur tekstual.

Hadirnya sebuah karya sastra memiliki hubungan yang erat dengan pengarang dan masyarakat (pembaca). Pembacalah yang akan memberikan makna dan arti pada karya tersebut. Pengarang menghasilkan karya karena kreativitasnya. Tentu saja ia ingin menyampaikan pesan kepada masyarakat pembacanya melalui karya sastra, yaitu suatu aspek budaya yang dapat dipakai untuk mengkomunikasikan kehendak (pesan) pengarang kepada pembaca. Di sisi lain, karya sastra dapat dipandang sebagai dokumentasi budaya, sejarah, atau refleksi kehidupan masyarakat pada saat karya itu dihasilkan. Oleh sebab itu, pembacalah yang akan menafsirkan karya sastra tersebut.

Teks sastra menurut Istanti (2008: 24) adalah suatu produk seni yang diciptakan dengan unsur estetika. Suatu teks sastra sebelum terjangkau oleh pembaca masih berupa artefak dan baru berwujud sebagai objek estetik melalui partisipasi aktif pembacanya (di antaranya terlihat dalam bentuk-bentuk kreativitasnya). Iser (1978: 20) menyatakan bahwa pusat dari pembacaan semua karya sastra adalah interaksi antara struktur dan penerimanya. Jadi, pemaknaan terhadap suatu karya sastra akan menimbulkan pemaknaan yang berbeda. Kalau menurut Umar Junus hal tersebut merupakan polisemi. Iser menambahkan bahwa studi karya sastra harus memperhatikan tindakan yang terlibat 
dalam merespon suatu teks, tidak hanya mempertimbangkan teks aktualnya. Hal tersebut tampak dalam pendapat sebagai berikut:

"Central to the reading of every literary work is the interaction between its structure and its recipient. This is why the phenomenologycal theory of art has emphatically drawn attention to the fact that the study a literary work should concern not only the actual text but also and in equal measure, the actions involved in responding to that text. The text itself simply offers "scematized aspect" (the phrase is Roman Ingarden's) through which the subject matter of the work can be produced, while the actual production takes place through an act of concretization (Wolfgang Iser" (1978: 20-21).

Berdasarkan pendapat Wolfgang Iser di atas dapat diketahui bahwa pemaknaan pembaca terhadap suatu karya sastra akan berbeda-beda tergantung pada skemata pembaca. Senada dengan hal tersebut (Soeratno, 1991: 21) berpendapat bahwa realisasi teks berupa resepsi (tanggapan) dan penafsiran yang berbeda-beda dari para pembaca karena mereka telah dibekali dengan pengalaman dan pengetahuan yang berbeda-beda pula sehingga ada kemungkinan satu karya sastra memperoleh pemaknaan yang berbeda-beda dari suatu kelompok pembaca. Jadi dalam hal ini peran pembaca memiliki kedudukan yang penting.

Mendukung pendapat di atas, Ratna (2005: 208) menjelaskan bahwa teori resepsi melokasikan pembaca ke dalam posisi sentral. Pembaca adalah mediator, tanpa pembaca karya sastra seolah-olah tidak memiliki arti. Tanpa peran serta audiens, seperti pendengar, penikmat, penonton, pemirsa, penerjemah, dan para pengguna lainnya, khususnya pembaca itu sendiri, maka aspek-aspek kultural seolah-olah kehilangan maknanya.

Berdasarkan berbagai pendapat di atas, dapat disimpulkan bahwa resepsi sastra adalah tanggapan-tanggapan atau resepsiresepsi pembaca, baik secara perseorangan maupun secara bersama-sama atau secara massal terhadap karya sastra, serta tanggapan-tanggapan tersebut dipengaruhi oleh proses sejarah, pembaca dalam periode tertentu. Oleh sebab itu tanggapan-tanggapan yang mengarah pada pemaknaan teks karya sastra tersebut berbeda-beda tergantung pada mindset atau skemata pembaca.

\section{Ekranisasi}

Salah satu kajian yang digunakan dalam penelitian resepsi sastra adalah ekranisasi. Sebuah proses untuk mengetahui perbedaan antara novel dengan film. Ekranisasi lebih banyak menekankan perbedaan antara novel dengan film disebabkan karena perbedaan sistem sastra (novel) dengan sistem film. Eneste (1991: 60) menjelaskan bahwa alat utama dalam novel adalah kata-kata, segala sesuatu disampaikan dengan kata-kata. Cerita, alur, latar, penokohan, suasana, dan gaya sebuah novel dibangun dengan kata-kata. Pemindahan novel ke layar putih berarti terjadinya perubahan alat-alat yang dipakai, yakni mengubah dunia katakata menjadi dunia gambar-gambar yang bergerak berkelanjutan sebab di dalam film, cerita, alur, latar, penokohan, suasana, dan gaya diungkapkan melalui gambargambar yang bergerak berkelanjutan. Apa yang tadinya dilukiskan dengan kata-kata, kini harus diterjemahkan ke dunia gambargambar. Tentunya pemindahan dari novel ke dalam film akan memungkinkan terjadinya banyak perubahan. Teks atau kata-kata mampu membimbing imajinasi secara bebas, sedangkan visual memberikan bentuk 'nyata'. Teks juga mampu menggambarkan secara detail suasana hati, sudut lokasi secara berurutan berikut kiasan-kiasannya, serta memaparkan latar belakang persoalan secara kelindan. Namun, visual dengan sifatnya yang nyata, bukan berarti tidak mampu menggambarkan detail persoalan, suasana hati, dan latar belakang, akan tetapi memiliki karakteristik yang berbeda.

Bluestone (1956: 14-20) menjelaskan bahwa trnasformasi dari satu bentuk ke bentuk yang lain bisa dipastikan mengalami perubahan, karena karya tersebut harus menyesuaikan dengan media yang digunakan, dan masing-masing media memiliki 
konvensi tersendiri. Antara karya sastra yang tertulis menggunakan media bahasa dengan film yang menggunakan prinsip optikal berurusan dengan masalah penglihatan dan pendengaran sekaligus (audio visual) memiliki perlakuan berbeda terhadap karya.

Sementara itu, dalam lingkup yang lebih luas lagi transformasi karya yang dinamis bernaung dalam adaptasi, di dalamnya novelisasi film juga menjadi lahan (Pujiati, 2009: 76). Proses penggarapannya pun terjadi perubahan. Novel adalah kreasi individual dan merupakan hasil kerja perseorangan. Seseorang yang memiliki pengalaman, pemikiran, ide atau hal lain dapat saja melukiskannya di atas kertas dan jadilah sebuah novel yang siap untuk dibaca orang lain, namun tidak demikian dengan pembuatan film. Film merupakan hasil kerja banyak orang, tim produksi film tersebut. Bagus tidaknya sebuah film banyak ditentukan oleh keharmonisan kerja unit-unit di dalamnya, seperti produser, penulis skenario, sutradara, juru kamera, penata artistik, perekam suara, para pemain, dan lain-lain. Dengan kata lain, ekranisasi berarti proses perubahan dari sesuatu yang dihasilkan secara individual menjadi sesuatu yang dihasilkan secara bersama-sama.

Ekranisasi bisa juga diartikan sebagai terjadinya perubahan pada proses penikmatan. Novel dinikmati dengan membaca, sementara film cara menikmatinya dengan menonton. Begitu juga perubahan dari sebuah bentuk kesenian yang bisa dinikmati pada saat-saat tertentu dan tempat-tempat tertentu pula. Ekranisasi berarti pula apa yang dinikmati selama berjam-jam atau berhari-hari harus diubah menjadi apa yang dinikmati (ditonton) selama 90 sampai 120 menit (Eneste, 1991: 60-61).

Karya sastra mengajak pembaca berimajinasi secara bebas mengikuti cerita. Pembaca bebas memiliki imajinasi tentang gambaran tokoh, latar, dan suasana dalam cerita. Di samping itu, dalam sebuah karya sastra tidak jarang pengarang berhasil memancing rasa penasaran pembaca dengan permainan kata-katanya. Inilah sebabnya kata-kata merupakan hal yang sangat penting dalam sebuah karya sastra. Seorang pengarang membangun cerita menggunakan kata-kata.

Berbeda dengan karya sastra, film berbicara menggunakan gambar. Penulis skenario Pudovkin (dalam Eneste, 1991: 16) yang bergulat dengan plastic material mengatakan jika penulis skenario harus cermat memilih materi yang bisa membawa gambaran yang tepat bagi filmnya. Pemilihan materi sebuah rumah mewah dengan isi perabotan yang juga mewah kiranya telah cukup memberi gambaran kepada penonton bahwa tokoh yang digambarkan adalah orang kaya. Penentuan lokasi shooting di pedesaan cukup memberi gambaran mengenai latar cerita. Inilah yang disebut sebagai plastic material.

Ekranisasi adalah bentuk intertekstual dan resepsi terhadap sebuah karya. Seorang pembaca yang aktif akan melahirkan sebuah karya baru sebagai wujud apresiasi terhadap sebuah karya. Perubahan yang muncul merupakan wujud dari apa yang disebut Jauss sebagai horison harapan pembaca. Kolker (2002: 128) menyatakan bahwa intertekstualitas (dalam film) adalah sebuah persepsi beberapa teks dengan mempertimbangkan budaya yang berkembang pada saat itu. Jadi, wajar, jika sebuah karya masa lalu muncul kembali dengan wajah masa kini. Ekranisasi dapat dikatakan sebagai salah satu bentuk interpretasi pembaca yang aktif sehingga melahirkan sebuah karya baru. Berbekal pengetahuan dan latar sosial budaya tertentu, pembuat film dapat melahirkan sebuah karya sebagai wujud perombakan terhadap karya sebelumnya.

\section{Sinopsis Novel KCB}

Azzam adalah seorang mahasiswa asal Indonesia yang sedang menuntut studi di Universitas Al-Azhar Cairo. Untuk kebutuhan biaya kuliahnya, ia bekerja sebagai seorang penjual tempe. Keluarganya tinggal di Surakarta, Indonesia. Secara ekonomis dan akademis, prestasi Azzam masih di bawah Furqon, mahasiswa asal Indonesia yang 
memiliki prestasi akademis yang baik dan berasal dari keluarga kaya.

Suatu ketika, Azzam tanpa sengaja berkenalan dengan seorang muslimah yang sangat cantik bernama Anna Althafunnisa, seorang mahasiswi yang juga berasal dari Indonesia. Selain itu, Azzam cukup akrab dengan seorang anak duta besar bernama Eliana. Meskipun Eliana menaruh perasaan pada Azzam, tetapi tidak sebaliknya.

Azzam pun memutuskan untuk menikah. Ia menemui Ustadz Mujab untuk melamar Anna, seorang gadis yang sudah membuat hati dan perasaannya tertarik. Namun betapa terkejutnya Azzam saat ia datang melamar Anna, ternyata Anna telah dalam pinangan Furqon. Tidak ada alasan bagi Ustadz Mujab untuk lebih mengutamakan Azzam dari pada Furqon. Azzam pun akhirnya mundur. Setelah lulus kuliah, ia pun memutuskan pulang ke tanah air dan diikuti oleh Eliana. Sesampai di tanah air, ia dikejutkan dengan berita akan segera dilangsungkannya pernikahan Anna dengan Furqon.

Azzam pun ikhlas dengan takdir Tuhan yang telah ditetapkan atas dirinya. Ia turut menghadiri pesta pernikahan Anna dan Furqon. Namun rupanya Tuhan memberikan takdir lain pada hamba-Nya yang ikhlas. Pada malam pertama dan malam-malam selanjutnya, Furqon tidak bisa menunaikan kewajibannya sebagai seorang suami disebabkan trauma atas insiden yang ia alami bersama seorang wanita penghibur di sebuah hotel.

Furqon dituduh mengidap virus HIV. Pertikaian tidak bisa dihindari. Anna dan Furqon pun akhirnya bercerai. Azzam tidak mengetahui jika Anna telah bercerai dari Furqon. Lelah mencari jodoh yang sesuai dengan dirinya, Azzam pun menemui ayahanda Anna. Azzam pasrah minta dicarikan jodoh pada ayah Anna. Ayah Anna pun akhirnya mempertemukan Anna dan Azzam dengan cara yang baik dan suci dalam ikatan pernikahan. Azzam sebenarnya sejak awal adalah pemuda dambaan Anna, pun sebaliknya.

\section{PEMBAHASAN}

\section{Transformasi Novel KCB ke Film KCB}

Para pembaca novel masing-masing memiliki imajinasi saat akan menonton film KCB berdasarkan skematanya dan tentunya antar pembaca memiliki skemata yang berbeda. Saat membaca novel, pembaca menggambarkan bagaimana tokoh-tokoh dalam novel, keindahan kota Cairo, dan hal-hal lain yang terdapat dalam novel. Umumnya jika gambaran dalam novel tidak sesuai dengan isi filmnya, maka pembaca akan mengatakan kalau filmnya tidak bagus. Hal ini berdasarkan konsep bahwa film yang merupakan hasil ekranisasi dari novel yang bagus adalah yang mendekati/banyak memiliki persamaan dengan isi novel.

Namun, ada pula pembaca novel dan sudah menonton film KCB menilai bahwa filmnya bagus. Hal tersebut berdasarkan konsep bahwa antar novel dengan film merupakan dua hal yang berbeda, sehingga penilaian bagus dan tidaknya bukan pada tingkat kesamaan antara novel dengan film. Justru film KCB dinilai bagus karena bisa menutup kekurangan-kekurangan yang terdapat dalam novel.

Tabel 1

Detail Makna Antara Novel dan Film

\begin{tabular}{l|l|l|l}
\hline No. & \multicolumn{1}{|c|}{ Novel } & \multicolumn{1}{c}{ Film } & \multicolumn{1}{c}{ Maknanya } \\
\hline 1. & $\begin{array}{l}\text { Di lobby hotel, Elianan mengenakan } \\
\text { kaos lengan panjang ketat berwarna } \\
\text { merah muda dan celana jeans putih } \\
\text { ketat saat meminta bantuan Azzam } \\
\text { untuk membuat nasi panas berlaukl } \\
\text { ikan bakar dan sambal pedas khas } \\
\text { Yogyakarta. }\end{array}$ & $\begin{array}{l}\text { Eliana mengenakan } \\
\text { pakaian atasan warna } \\
\text { putih dan tidak ketat. }\end{array}$ & $\begin{array}{l}\text { Representasi di film dibuat lebih } \\
\text { sopan untuk kebutuhan artistik } \\
\text { film. }\end{array}$ \\
\hline
\end{tabular}


Lanjutan Tabel 1

\begin{tabular}{|c|c|c|c|}
\hline No. & Novel & Film & Maknanya \\
\hline 2. & $\begin{array}{l}\text { Ada cerita Azzam mencari bumbu } \\
\text { ikan bakar dengan Pak Ali di pasar. }\end{array}$ & $\begin{array}{l}\text { Tidak ada adegan } \\
\text { Azzam mencari } \\
\text { bumbu ikan bakar } \\
\text { dengan Pak Ali di } \\
\text { pasar. }\end{array}$ & $\begin{array}{l}\text { Untuk keefektifan cerita karena } \\
\text { di dalam film memerlukan } \\
\text { banyak durasi untuk penam- } \\
\text { bahan adegan baru sehingga ada } \\
\text { cerita di novel yang tidak perlu } \\
\text { ditampilkan dalam film. }\end{array}$ \\
\hline 3. & $\begin{array}{l}\text { Pembicaraan antara Azzam dengan } \\
\text { Pak Ali di Pantai Cleopatra agak } \\
\text { panjang. }\end{array}$ & $\begin{array}{l}\text { Pembicaraan antara } \\
\text { Azzam dengan } \\
\text { Pak Ali di Pantai } \\
\text { Cleopatra dibuat } \\
\text { singkat dan langsung } \\
\text { mengarah kepada } \\
\text { penawaran Pak } \\
\text { Ali agar Azzam } \\
\text { mengkhitbah Anna } \\
\text { Althafunnisa. }\end{array}$ & $\begin{array}{l}\text { Untuk keefektifan cerita karena } \\
\text { di dalam film memerlukan } \\
\text { banyak durasi untuk } \\
\text { penambahan adegan baru } \\
\text { sehingga ada cerita di novel } \\
\text { yang tidak perlu ditampilkan } \\
\text { dalam film. }\end{array}$ \\
\hline 4. & $\begin{array}{l}\text { Terdapat cerita kalau Azzam } \\
\text { membeli makanan Habasy takanat } \\
\text { untuk Eliana dan dititipkan Pak Ali. }\end{array}$ & $\begin{array}{l}\text { Tidak ada adegan } \\
\text { kalau Azzam membeli } \\
\text { makanan Habasy } \\
\text { takanat untuk Eliana } \\
\text { dan dititipkan Pak Ali. }\end{array}$ & $\begin{array}{l}\text { Untuk keefektifan cerita karena } \\
\text { di dalam film memerlukan } \\
\text { banyak durasi untuk penam- } \\
\text { bahan adegan baru sehingga ada } \\
\text { cerita di novel yang tidak perlu } \\
\text { ditampilkan dalam film. }\end{array}$ \\
\hline 5. & Mobil Furqan berwarna putih. & $\begin{array}{l}\text { Mobil Furqan } \\
\text { berwarna hitam. }\end{array}$ & $\begin{array}{l}\text { Untuk memudahkan visualisasi } \\
\text { film. }\end{array}$ \\
\hline 6. & $\begin{array}{l}\text { Hafez curhat kalau ia menyukai } \\
\text { Cut Mala ke Azzam setelah subuh } \\
\text { karena Azzam sangat lelah. }\end{array}$ & $\begin{array}{l}\text { Hafez langsung curhat } \\
\text { ke Azzam sebelum } \\
\text { subuh. }\end{array}$ & $\begin{array}{l}\text { Untuk keefektifan cerita karena } \\
\text { di dalam film memerlukan } \\
\text { banyak durasi untuk penam- } \\
\text { bahan adegan baru sehingga ada } \\
\text { cerita di novel yang tidak perlu } \\
\text { ditampilkan dalam film. }\end{array}$ \\
\hline 7. & $\begin{array}{l}\text { Dijelaskan terdapat foto-foto } \\
\text { Furqan dengan Miss Italiana di } \\
\text { internet. }\end{array}$ & $\begin{array}{l}\text { Tidak terdapat } \\
\text { foto-foto Furqan } \\
\text { dengan Miss Italiana } \\
\text { di internet, cuma } \\
\text { pendeskripsian } \\
\text { dengan kata-kata. } \\
\end{array}$ & $\begin{array}{l}\text { Di Film, tindakan tidak senonoh } \\
\text { yang berupa gambar-gambar } \\
\text { porno sengaja tidak ditampilkan } \\
\text { untuk menjaga adab pergaulan } \\
\text { antar pemain agar tetap sesuai } \\
\text { syariat Islam. }\end{array}$ \\
\hline 8. & $\begin{array}{l}\text { Kolonel Fuad meminta tambahan } \\
\text { upah, tidak hanya seribu pound, } \\
\text { tetapi Furqan juga berjanji akan } \\
\text { menyerahkan mobil fiat putihnya } \\
\text { ke kolonel jika kasusnya selesai } \\
\text { diatasi. }\end{array}$ & $\begin{array}{l}\text { Tidak ada adegan } \\
\text { Kolonel Fuad } \\
\text { meminta tambahan } \\
\text { upah kepada Furqan. }\end{array}$ & $\begin{array}{l}\text { Untuk mempersingkat cerita } \\
\text { demi keefektifan durasi waktu } \\
\text { dalam film. }\end{array}$ \\
\hline 9. & $\begin{array}{l}\text { Azzam bertanya kepada Anna } \\
\text { kitab-kitab apa saja yang dibeli } \\
\text { Anna yang tertinggal di bus. }\end{array}$ & $\begin{array}{l}\text { Tidak ada adegan } \\
\text { kalau Azzam bertanya } \\
\text { kepada Anna kitab- } \\
\text { kitab apa saja yang } \\
\text { dibeli Anna yang } \\
\text { tertinggal di bus. }\end{array}$ & $\begin{array}{l}\text { Untuk keefektifan cerita karena } \\
\text { di dalam film memerlukan } \\
\text { banyak durasi untuk penam- } \\
\text { bahan adegan baru sehingga ada } \\
\text { cerita di novel yang tidak perlu } \\
\text { ditampilkan dalam film. }\end{array}$ \\
\hline
\end{tabular}


Lanjutan Tabel 1

\begin{tabular}{|c|c|c|c|}
\hline No. & Novel & Film & Maknanya \\
\hline 10. & $\begin{array}{l}\text { Novel KCB } 2 \text { diawali dengan } \\
\text { tatapan Anna menikmati indahnya } \\
\text { desa Wangen dari jendela } \\
\text { kamarnya. }\end{array}$ & $\begin{array}{l}\text { Adegan tatapan Anna } \\
\text { menikmati indahnya } \\
\text { desa Wangen dari } \\
\text { jendela kamarnya } \\
\text { tidak ditampilkan, } \\
\text { tetapi langsung meng- } \\
\text { arah kepada anjuran } \\
\text { Kyai Luthfi agar Anna } \\
\text { segera menikah. } \\
\end{array}$ & $\begin{array}{l}\text { Untuk keefektifan cerita karena } \\
\text { di film membutuhkan banyak } \\
\text { durasi untuk adegan baru. }\end{array}$ \\
\hline 11. & $\begin{array}{l}\text { Azzam lulus S-1 dengan melihat } \\
\text { sendiri di papan pengumuman. }\end{array}$ & $\begin{array}{l}\text { Azzam lulus S-1 } \\
\text { diberi tahu temannya } \\
\text { (Miftah) sebelum ia } \\
\text { sendiri melihat di } \\
\text { papan pengumuman. }\end{array}$ & $\begin{array}{l}\text { Untuk membangun konflik } \\
\text { utama film sehingga alur } \\
\text { ceritanya jelas sesuai kebutuhan } \\
\text { cerita dalam film. }\end{array}$ \\
\hline 12. & $\begin{array}{l}\text { Furqan melakukan tes darah dua } \\
\text { kali. }\end{array}$ & $\begin{array}{l}\text { Furqan melakukan tes } \\
\text { darah sekali saja. }\end{array}$ & $\begin{array}{l}\text { Untuk keefektifan cerita karena } \\
\text { di film membutuhkan banyak } \\
\text { durasi untuk adegan baru. }\end{array}$ \\
\hline 13. & $\begin{array}{l}\text { Terdapat syair lagu yang } \\
\text { didendangkan Fadhil pada } \\
\text { pernikahan Tiara yang berbunyi } \\
\text { "Mari kita sama-sama insaf...." }\end{array}$ & \begin{tabular}{|l|} 
Tidak terdapat syair \\
lagu yang didendang- \\
kan Fadhil pada \\
pernikahan Tiara yang \\
berbunyi "Mari kita \\
sama-sama insaf...." \\
\end{tabular} & $\begin{array}{l}\text { Untuk keefektifan cerita karena } \\
\text { di film membutuhkan banyak } \\
\text { durasi untuk adegan baru. }\end{array}$ \\
\hline 14. & $\begin{array}{l}\text { Dalam acara khitbah, Furqan dan } \\
\text { Anna mengenakan baju biru. }\end{array}$ & $\begin{array}{l}\text { Dalam acara khitbah, } \\
\text { Furqan mengenakan } \\
\text { jas hitam, sedangkan } \\
\text { Anna mengenakan } \\
\text { gamis putih dengan } \\
\text { jilbab kuning } \\
\text { kehijauan. }\end{array}$ & $\begin{array}{l}\text { Selain untuk kebutuhan artistik } \\
\text { film, juga untuk mengukuhkan } \\
\text { sosok Furqan yang kaya. }\end{array}$ \\
\hline 15. & $\begin{array}{l}\text { Terdapat cerita kalau Husna dan } \\
\text { Azzam berpelukan saat bertemu } \\
\text { di bandara, sesaat setelah Azzam } \\
\text { sampai di Indonesia. }\end{array}$ & $\begin{array}{l}\text { Tidak terdapat adegan } \\
\text { Husna dan Azzam } \\
\text { berpelukan saat } \\
\text { bertemu di bandara, } \\
\text { sesaat setelah Azzam } \\
\text { sampai di Indonesia. }\end{array}$ & $\begin{array}{l}\text { Adegan film dibuat agar tetap } \\
\text { sesuai syariat karena para } \\
\text { pemain bukan mahram sehing- } \\
\text { ga adegan berpelukan tidak } \\
\text { ditampilkan, tetapi diganti } \\
\text { dengan adegan lain yang tetap } \\
\text { mendukung. }\end{array}$ \\
\hline 16. & $\begin{array}{l}\text { Diawali dengan indahnya } \\
\text { pemandangan desa Wangen. }\end{array}$ & $\begin{array}{l}\text { Diawali dengan Husna } \\
\text { menerima penghargaan } \\
\text { sebagai penulis terbaik } \\
\text { tingkat nasional. }\end{array}$ & $\begin{array}{l}\text { Untuk mendapatkan unsur } \\
\text { dramatik dalam film dan } \\
\text { keterjalinan antarunsur. }\end{array}$ \\
\hline 17. & $\begin{array}{l}\text { Ada cerita tentang Zumrah dan } \\
\text { masalah yang menimpanya. }\end{array}$ & $\begin{array}{l}\text { Adegan cerita Zumrah } \\
\text { tidak ditampilkan. }\end{array}$ & $\begin{array}{l}\text { Untuk keefektifan cerita karena } \\
\text { di film membutuhkan banyak } \\
\text { durasi untuk adegan baru. } \\
\text { Apalagi tokoh Zumrah tidak } \\
\text { begitu berperan penting dalam } \\
\text { novel maupun film. }\end{array}$ \\
\hline
\end{tabular}


Lanjutan Tabel 1

\begin{tabular}{|c|c|c|c|}
\hline No. & Novel & Film & Maknanya \\
\hline 18. & $\begin{array}{l}\text { Ketika Azzam mengantar buku- } \\
\text { buku Anna ke rumahnya, dia } \\
\text { disuguhi nasi goreng yang } \\
\text { dibungkus telur. }\end{array}$ & $\begin{array}{l}\text { Tidak ada adegan } \\
\text { Azzam disuguhi Anna } \\
\text { dengan nasi goreng } \\
\text { yang dibungkus telur } \\
\text { ketika mengantar } \\
\text { buku-buku Anna dari } \\
\text { Mesir. }\end{array}$ & $\begin{array}{l}\text { Untuk keefektifan cerita karena } \\
\text { di film membutuhkan banyak } \\
\text { durasi untuk adegan baru. }\end{array}$ \\
\hline 19. & $\begin{array}{l}\text { Anna membuka auratnya dalam } \\
\text { malam pertamanya dengan Furqan. }\end{array}$ & $\begin{array}{l}\text { Anna membuka } \\
\text { auratnya dalam } \\
\text { malam pertamanya } \\
\text { dengan Furqan. }\end{array}$ & $\begin{array}{l}\text { Agar sesuai syariat Islam } \\
\text { karena para pemain film bukan } \\
\text { mahram. }\end{array}$ \\
\hline 20. & $\begin{array}{l}\text { Furqan dan Anna menginap di } \\
\text { hotel Novotel ketika Furqan ingin } \\
\text { berterus terang bahwa dia terkena } \\
\text { HIV. }\end{array}$ & $\begin{array}{l}\text { Furqan dan Anna } \\
\text { menginap di hotel } \\
\text { Lor Inn ketika Furqan } \\
\text { ingin berterus terang } \\
\text { bahwa dia terkena } \\
\text { HIV. }\end{array}$ & $\begin{array}{l}\text { Untuk mendapatkan adegan } \\
\text { yang tidak membosankan, } \\
\text { adegan di film terkesan lebih } \\
\text { teatrikal, akan berbeda jika } \\
\text { apa yang ada dalam novel } \\
\text { ditampilkan begitu saja tanpa } \\
\text { perubahan. }\end{array}$ \\
\hline 21. & $\begin{array}{l}\text { Setelah dari hotel Novotel, Anna } \\
\text { menginap di hotel Quality. }\end{array}$ & \begin{tabular}{|l|} 
Setelah dari hotel \\
Novotel, Anna \\
langsung pulang ke \\
desa Wangen dan \\
langsung menjelaskan \\
kepada abahnya \\
bahwa dia telah \\
bercerai. \\
\end{tabular} & $\begin{array}{l}\text { Untuk mendapatkan adegan } \\
\text { yang tidak membosankan, } \\
\text { adegan di film terkesan lebih } \\
\text { teatrikal, akan berbeda jika } \\
\text { apa yang ada dalam novel } \\
\text { ditampilkan begitu saja tanpa } \\
\text { perubahan. }\end{array}$ \\
\hline 22. & $\begin{array}{l}\text { Tidak disebutkan kalau Furqan tes } \\
\text { darah beberapa kali lagi. }\end{array}$ & $\begin{array}{l}\text { Ada adegan bahwa } \\
\text { Furqan beberapa kali } \\
\text { tes darah lagi untuk } \\
\text { memastikan bahwa } \\
\text { dia tidak terkena HIV. }\end{array}$ & $\begin{array}{l}\text { Untuk mendapatkan adegan } \\
\text { yang tidak membosankan, } \\
\text { adegan di film terkesan lebih } \\
\text { teatrikal, akan berbeda jika } \\
\text { apa yang ada dalam novel } \\
\text { ditampilkan begitu saja tanpa } \\
\text { perubahan. }\end{array}$ \\
\hline 23. & $\begin{array}{l}\text { Anna dan Azzam melakukan } \\
\text { malam pertama yang memang } \\
\text { diceritakan layalnya sebagai suami- } \\
\text { isteri. }\end{array}$ & $\begin{array}{l}\text { Anna dan Azzam } \\
\text { melakukan malam } \\
\text { pertama hanya } \\
\text { dengan duduk berdua } \\
\text { dan bercanda. }\end{array}$ & $\begin{array}{l}\text { Adegan film dibuat agar } \\
\text { tetap sesuai syariat karena } \\
\text { para pemain bukan mahram } \\
\text { sehingga adegan berpelukan } \\
\text { tidak ditampilkan, tetapi diganti } \\
\text { dengan adegan lain yang tetap } \\
\text { mendukung. } \\
\end{array}$ \\
\hline 24. & $\begin{array}{l}\text { Furqan dan ibunya ke desa Wangen } \\
\text { menemui Kyai Luthfi kalau dia } \\
\text { tidak terkena HIV dan ingin } \\
\text { kembali rujuk dengan Anna. }\end{array}$ & $\begin{array}{l}\text { Furqan memberi tahu } \\
\text { Anna bahwa dirinya } \\
\text { tidak terkena HIV via } \\
\text { email. }\end{array}$ & $\begin{array}{l}\text { Untuk mendapatkan adegan } \\
\text { yang tidak membosankan, } \\
\text { adegan di film terkesan lebih } \\
\text { teatrikal, akan berbeda jika } \\
\text { apa yang ada dalam novel } \\
\text { ditampilkan begitu saja tanpa } \\
\text { perubahan. }\end{array}$ \\
\hline
\end{tabular}


Lanjutan Tabel 1

\begin{tabular}{|c|c|c|c|}
\hline No. & Novel & Film & Maknanya \\
\hline 25. & $\begin{array}{l}\text { Tidak ada cerita yang menceritakan } \\
\text { bahwa setelah menikah dengan } \\
\text { Azzam, Anna dan adik-adik Azzam } \\
\text { jalan-jalan satu mobil. }\end{array}$ & $\begin{array}{l}\text { Terdapat adegan } \\
\text { Anna jalan-jalan } \\
\text { dengan Azzam dan } \\
\text { adik-adiknya satu } \\
\text { mobil. }\end{array}$ & $\begin{array}{l}\text { Merupakan kelanjutan adegan } \\
\text { sebelumnya, yaitu untuk } \\
\text { mendapatkan suasana yang } \\
\text { mengharukan dan bahagia, } \\
\text { Anna bisa hidup berdampingan } \\
\text { dengan Azzam dan keluarganya. }\end{array}$ \\
\hline
\end{tabular}

\section{SIMPULAN}

Para pembaca novel masing-masing memiliki imajinasi saat akan menonton film KCB berdasarkan skematanya dan tentunya antarpembaca memiliki skemata yang berbeda. Saat membaca novel, pembaca menggambarkan bagaimana tokoh-tokoh dalam novel, keindahan kota Cairo, dan hal-hal lain yang terdapat dalam novel. Umumnya jika gambaran dalam novel tidak sesuai dengan isi filmnya, maka pembaca akan mengatakan kalau filmnya tidak bagus. Hal ini berdasarkan konsep bahwa film yang merupakan hasil ekranisasi dari novel yang bagus adalah yang mendekati/banyak memiliki persamaan dengan isi novel. Pembaca yang masuk dalam kategori tersebut adalah para pembaca awam yang belum atau kurang memahami teori sastra maupun sinematografi. Mereka itu adalah masyarakat umum biasa, termasuk juga tokoh agama.

Akan tetapi, ada pula pembaca novel dan sudah menonton film KCB menilai bahwa filmnya bagus. Hal tersebut berdasarkan konsep bahwa antar novel dengan film merupakan dua hal yang berbeda sehingga penilaian bagus dan tidaknya bukan pada tingkat kesamaan antara novel dengan film. Justru film KCB dinilai bagus karena bisa menutup kekurangan-kekurangan yang terdapat dalam novel.

Marxis dan formalis mengabaikan peranan pembaca, pendengar, penonton, dan audiens pada umumnya, dengan teori-teori sosial lain yang mengabaikan teks. Marxis (ortodoks) menganggap bahwa pembaca sama dengan penulis, hanya meneliti posisi sosialnya, sedangkan formalis menganggap pembaca sebagai subjek yang harus mengikuti petunjuk-petunjuk teks. Marxis menganggap karya sebagai representasi kenyataan, sedangkan formalis memandangnya sebagai representasi estetis. Meskipun model resepsi memberikan perhatian pada sejarah penerimaan, bukan berarti bahwa teori resepsi merupakan sejarah asal usul. Sebaliknya, teori resepsi adalah sejarah relasi sebab yang dicari adalah mata rantai tanggapan pembaca. Unsur kesejarahan dalam hubungan ini terjadi selama proses pembacaan berlangsung. Sejarah sastra dapat dibangun semata-mata atas dasar hubungan timbal balik antara karya sastra dengan audiens, dari penerimaan pasif menjadi aktif, dari norma estetis yang telah dimilikinya menjadi norma baru yang diproduksinya.

Akhirnya, hendaknya masyarakat mengenal ekranisasi sehingga tidak asumtif, subjektif, dan apriori dalam memberikan penilaian terhadap karya seni (novel dan film), cinta terhadap karya seni sehingga bisa meneladani amanat (pesan) yang terkandung di dalamnya untuk diamalkan dalam kehidupan sehari-hari, dan lebih apresiatif dan memberikan penghargaan yang baik terhadap karya seni.

\section{DAFTAR PUSTAKA}

Bluestone, G. (1956). Novel Into Film. Berkeley Los Angeles, London: University of California Press.

Hadiansyah, F. (2006). Adaptasi Novel Biola Tak Berdawai ke dalam Film: Kajian Perbandingan. Jakarta: PPs Universitas Indonesia.

Iser, W. (1978). The Act of Readings: A Theory of Aesthetic Response. London: The Johns Hopkins University Press. 
Pujiati, H. (2009). Cerita Cinta tentang Dia: Transformasi Ideologis dari Cerpen ke Film Kajian Ekranisasi. Jurnal Bulak, 4.

Kolker, R. P. (2002). Film, Form, and Culture. New York: Mc Graw-Hill Education.

Istanti, K. Z. (2008). Sambutan Hikayat Amir Hamzah dalam Sejarah Melayu, Hikayat Umar Umayah, dan Serat Menak. Yogyakarta: FIB UGM Press.

Ratna, N. K. (2005). (a). Sastra dan Cultural Studies Representasi Fiksi dan Fakta. Yogyakarta: Pustaka Pelajar. (2009) (b). Teori, Metode, dan Teknik Penelitian Sastra. Yogyakarta: Pustaka Pelajar.

Eneste, P. 1991. Novel dan Film. Flores: Penerbit Nusa Indah.
Pradopo, R. Dj. (2008). Beberapa Teori Sastra, Metode Kritik, dan Penerapannya. Yogyakarta: Pustaka Pelajar.

Sangidu. (2002). Karya Syaikh Muhammad Fadhlullah Al-Burhanpuri: Kajian Filologis dan Analisis Resepsi. Humaniora, XIV.

Sayuti, S. A. (2000). Evaluasi Teks Sastra. Yogyakarta: Adicita.

Soeratno, S. Ch.. (1991). Hikayat Iskandar Zulkarnain: Analisis Resepsi. Jakarta: Balai Pustaka.

Sastriyani, S. H. (2001). Karya Sastra Perancis Abad ke-19 Madame Bovary dan Resepsinya di Indonesia. Humaniora, XIII (3), 253.

Teeuw, A. (1988). Sastra dan Ilmu Sastra Pengantar Teori Sastra. Jakarta: PT Dunia Pustaka Jaya.

Junus, U. (1985). Resepsi Sastra: Sebuah Pengantar. Jakarta: PT Gramedia. 